\title{
Innovation Performance in Brazil - What is Missing? From the Perspective of Micro and Small Technology- Based Firms
}

\author{
Paulo Melo', Bill O’ Gorman², \\ Arnoldo José de Hoyos Guevara ${ }^{3}$, Renata Martins Corrêa ${ }^{4}$, \\ Danilo S. G. Valentim ${ }^{5}$ \\ ${ }^{1}$ Unifacs, Salvador - Brazil; \\ ${ }^{2}$ Waterford Institute of Technology, Ireland; \\ ${ }^{3}$ FEA - PUC-SP, São Paulo - Brazil; \\ ${ }^{4} \mathrm{FEI}$, São Paulo - Brazil, ${ }^{5}$ UNIP, São Paulo - Brazil \\ E-mail: arnoldodehoyos@yahoo.com.br,wogorman@tinet.ie, \\ pmmelo@yahoo.com, renatacorreaprof@gmail.com, \\ danilo_uk@hotmail.com
}

\begin{abstract}
The present paper approaches one of the most important themes in the business and economic areas since the second half of the 20th century: innovation; in particular for developing countries such as Brazil. For these countries, competitiveness is directly linked to the ability to foster and sustain a higher level of firms' innovativeness. In Brazil, despite the overall economic and innovation conditions such as the presence of relevant innovation agents (i.e. universities, government, research centres and investors) and access to financing mechanisms as well as public policies which facilitated innovation initiatives have apparently been improved, innovation rates does not take off. So, considering this context, the present paper tried to examine what problems were hampering or inhibiting the improvement and increasing of the level of country's innovativeness from the perspective of micro and small technology-based firms. The findings showed that there are still some problems such as lack of government support, funds and financing mechanisms as well as high costs of innovation and organizational resistances which play an important role pushing firms not to innovate.

Keywords: innovation, competitiveness, micro and small technology-based firms and interactions, developing countries.
\end{abstract}




\section{INTRODUCTION}

The fact that the phenomenon of innovation seems to be influenced by a wide variety of factors such as the development of new technologies, public policies and financing mechanisms among others, has provoked discussions in the past three decades among academics, government and society. The set of these factors impact economic growth, therefore is crucial to keep countries' economies moving forward. So, because of the increasing of importance and influence of the theme of innovation on the economic and social progress, the authors have decided to investigate innovation in Brazil.

This new social and economic scenario, based on themes such as globalization, competitiveness, innovativeness and new technologies have provoked discussions in how countries and companies compete with each other and experience decline and growth in the global arena (Rothwell, 1994, Porter, 1998; OECD, 1996 and 2000 and Svetina and Prodan, 2008); therefore, the long term capability of companies and countries to prosper and gain competitive advantage is now based on the continuous increasing of innovation initiatives (Best, 1990).

In this new paradigm of competitiveness, innovation has became a buzzword and presents itself as a thin line that separate those companies and countries which struggle to survive and those which have survived based on the continuous improvement of innovation performance, production flexibility and adaptability of organizational frontiers (Best, 1990)

Competitive countries and companies tend to be more prosperous as they have the ability to maintain a higher level of sustainable innovativeness; however, despite of some countries apparently have changed their overall economic factors, innovation conditions (access to some incentives and financing mechanisms, the presence of important innovation actors and relatively favorable institutional environment) does not necessarily are also improved. This seems to be the case of Brazil.

According to the Global Innovation Index (GII), Brazil is ranked in the 61th position among the countries surveyed. This scenario is also reflected considering the Brazilian Technological Innovation Survey (PINTEC) which innovation rate has not increased significantly. PINTEC is a national innovation survey, based on the Oslo Manual, performed by the Brazilian Institute of Statistics (IBGE) since 2002. PINTEC, version 2000, revealed that, on average, only three out of ten firms were involved in product or process innovation projects.

Since in the latest version of PINTEC survey (2011), innovation scenario has not changed: still three out of ten firms were involved in some product and services innovation projects (see Table 1). This survey also identified that innovation in those companies is still based primarily on access to technological knowledge through the purchase of machinery and equipment.

Considering the figures since the first version of the PINTEC survey, Brazilian government has tried to promote efforts in order to stimulate new innovation initiatives. Institutions such as the Research and Projects Financing Agency (FINEP), local State agencies and the Brazilian development bank (BNDES) were oriented to foster innovation activities among private companies, research centres and universities as well as to finance and fund research and development (R\&D) activities and innovation projects.

The BNDES, for instance, the main financial institution in Brazil established since 1952 was created to primarily to provide long-term financing tools able to stimulate sustainable economic 
and social development and to improve the competitiveness of the Brazilian economy also created financing lines at subsidized interest rates to stimulate companies to invest in innovation projects.

Despite all efforts to create mechanisms to stimulate and finance innovation activities in Brazil, structural economic problems and political dysfunctions affecting the country nowadays, indicate that those efforts were not so effective.

Table 1. Overall Innovation rate in Brazil

\begin{tabular}{c|c|c} 
Period & Number of firms surveyed & $\begin{array}{c}\text { \% Innovation Rate } \\
\text { National Average }\end{array}$ \\
\hline $1998-2000$ & 56,611 & $31,5 \%$ \\
\hline $2001-2003$ & 67,165 & $33,3 \%$ \\
\hline $2003-2005$ & 75,904 & $34,4 \%$ \\
\hline $2006-2008$ & 85,361 & $38,6 \%$ \\
\hline $2009-2011$ & 128,699 & $35,6 \%$
\end{tabular}

Source: IBGE (2000, 2003, 2005, 2008 e 2011)

Other surveys such as the latest version of the Global Innovation Index (GII, 2014) conducted by Johnson Cornel University, INSEAD and World Intellectual Property Organization (WIPO) also has confirmed that despite Brazil ranked 61st has improved its position comparing to 2013 (64th), it is not performing satisfactorily as far as innovation indicators (i.e. R\&D expenditures, infrastructure and others) are concerned (see Table 2). As a matter of fact, comparing with countries in Latin America such as Chile (ranked 46th) and Panama (ranked 52nd), Brazil is far behind. From the perspective of regions, Latin America (LA) is still far away from other regions like Europe, US and Canada (EUSAC) and even from South East Asia and Oceania(SEAO) as shown using Analysis of Variance (ANOVA) in Table 2: 
Table 2. Comparing Global Index among 3 Regions

One-way ANOVA: GII 2014 versus Regions

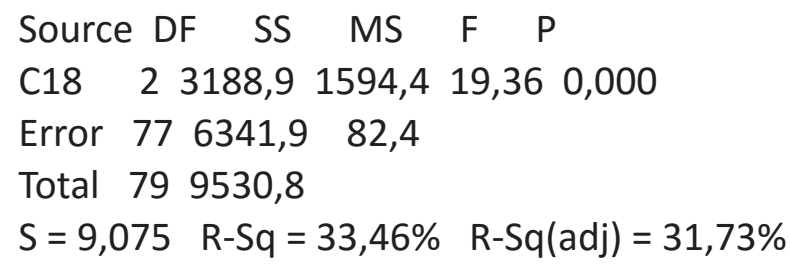

Individual 95\% Cls For Mean Based on

Pooled StDev

Level N Mean StDev --+---------+--------+--------+----

EUSAC $4147,7619,358 \quad\left(---*_{----)}\right.$

LA $22 \quad 32,859 \quad 4,541 \quad(-----* *----)$

SEAO 17 41,718 12,262 (------*------)

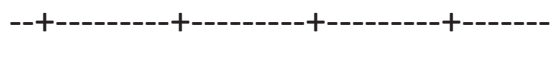

$30,0 \quad 36,0 \quad 42,0 \quad 48,0$

More specifically, Table 3 shows how Brazil is doing as far as innovation is concerned in comparison with other countries and Graph 1 compares countries in Latin America.

Table 3. Global Innovation Index Ranking

\begin{tabular}{c|c|c} 
Country & Rank & $\begin{array}{c}\text { Score (0-100) } \\
\text { National Average }\end{array}$ \\
\hline Switzerland & 01 & 64.78 \\
\hline United Kingdom & 02 & 62.37 \\
\hline United States of America & 06 & 60.09 \\
\hline Germany & 13 & 56.02 \\
\hline China & 29 & 46.57 \\
\hline Chile & 46 & 40.64 \\
\hline Brazil & 61 & 36.29
\end{tabular}

Source: GII (2014) 


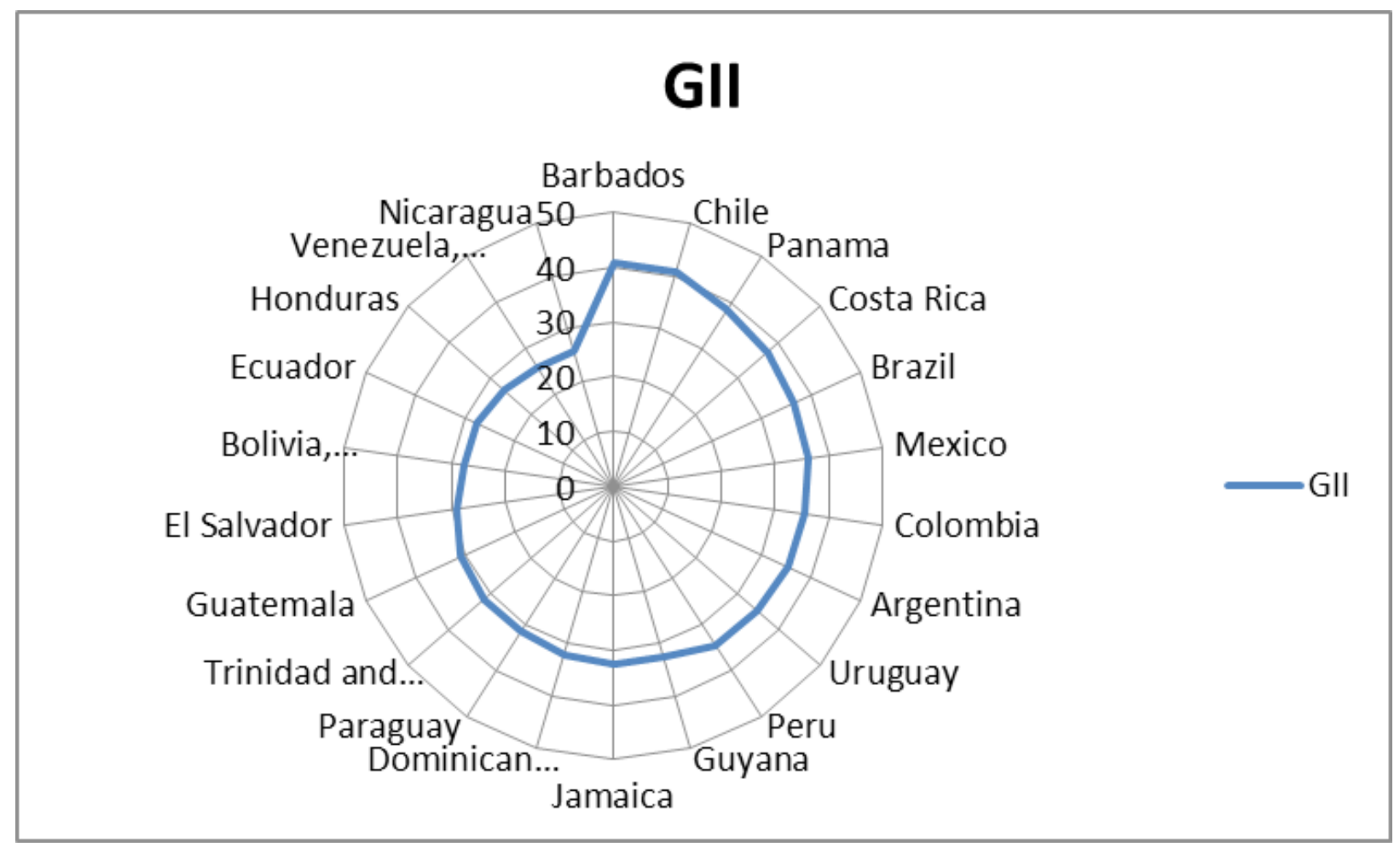

Graph 1. Countries in Latin America

Source: GII (2014)

In this context, innovation seems to be very relevant for improving Brazilian economic and social progress, as it seems to play a core role at the heart of any economic discussion and organizational changes around the world. Thus, the main contribution of the current paper to the discussion of innovation relies on the fact that despite the Brazilian government and companies have realized the increasing importance of the role of innovation on country's competitiveness, Brazil's innovation rate has not improved significantly. Thus, the problem approached in this study is to identify what problems and factors are hampering or inhibiting the improvement of the level of innovativeness of the Brazilian companies, what is missing and what may be done.

From this perspective, the purpose of this paper is not only to identify what factors are hampering the improvement innovation in the country, but to become a critical piece of study for entrepreneurs, government, policy makers and other stakeholders interested in the theme of innovation. The outcome of this paper may provide relevant information for government, institutions, universities, research centres and other stakeholders, able to suggest important clues for the development of sustained policies and strategies based on competitiveness and innovation.

\section{SOME CONSIDERATIONS ON INNOVATION - THE 21st CENTURY'S BUZZWORD}

Over the last decades, the theme of innovation has called attention of many scholars, government and entrepreneurs as both, business strategy and economic phenomenon. Researchers from many fields from economic geography to business management have been 
discussing innovation from their own perspective; thus innovation seems to be a multifaceted issue hardly explained by a single point of view.

Historically, innovation was studied from the perspective of economics. Economists from the Austrian school of economics (ASE) were the first to study innovation in early 1930's with emphasis on non math models to explain economic phenomenon. Scholars from this philosophical school of thought defended that human actions are also relevant to determine the course of economic scenarios.

In particular, innovation was considered a result of some forces such as free market, the increasing of competition and interactions of different economic actors. These set of forces resulted in a disruption of old models of business and production and created new business models (creative destruction, term coined by Schumpeter in 1942), stimulated the entrepreneurial spirit and interactions among social agents who are the main depository of knowledge, according to Kiessling and Richey (2004).

Considering this perspective, innovation seems to be considered a social and economic phenomenon and it is a result of firm's internal strategy, favourable external conditions (legal, political, economic and social etc.) and the level of interaction of those actors involved. Thus, both innovation influences the different external environments as well as influenced by them. One example is how new innovation initiatives within companies tend to lead to a more qualified labour and higher level of employment with relevant impact on the increase of employment rate with great impact on the local economic progress (Horbach and Rennings, 2013). This view is one of the main contributions of the Austrian School of Economics which are based on the understanding that innovation and economic phenomenon are interdisciplinary disciplines and can be explained not only by mathematical models but by the social context, perceptions and generation of new knowledge and technology.

From a narrow perspective, this paper approaches innovation considering the influence of internal (organizational) strategies and external forces (i.e. .social, economic, political etc.).

From the organizational perspective, Joseph Schumpeter, one of the most prominent economist from the Austrian school of economics, defined innovation as a complex mechanism of the introduction of a new product, process and service, method of production, opening of a new market, new source of raw material or the establishment of new businesses (Schumpeter, 1979). In late 2005', the Schumpeter's definition was the main reference used by the Oslo Manual to define innovation. The Oslo Manual defined innovation as, is any product/service, process or marketing and organizational changes which are new or significantly improved to the firm or to the market (OECD/Eurostat, 2005).

This methodology is internationally tested and recognized by the Organization for Economic Co-operation and Development (OECD) to measure and evaluate firm's innovation performance in various countries and has inspired many initiatives for standardizing survey methodology and technological innovation indicators ensuring comparability at international, regional, national and local levels.

Many other scholars have defined innovation according to their understanding. From the management perspective, Drucker (1986), for instance, defined innovation as a systematic phenomenon motivated by factors, such as: organizational factors such as internal R\&D projects 
(research and development), unexpected external or internal events, changes in the marketplace, some economic changes, demography, perceptions or the appearance of new knowledge. To Motta (1989), innovation is the outcome the discovery of a new opportunity,

the creative process or the use of uncommon tools to give creative solution to problems detected. To others, innovation is characterized by the exploitation of new opportunities regardless of whether firms use high technology or not (Holmen, Magnunsson and Mckelvey, 2007). So, innovation may be the result of new combinations of resources and market needs emerging from changes in customer preferences or new arrangements of economic agents.

In the last five or six decades, these concepts of innovation have changed and new elements from the social dimension were introduced such as the networking approach. One of the authors who explained this evolution of concepts of innovation from Schumpeter's creative destruction networking was Rothwell (1994). He suggested the "Rothwell Framework" which separated the evolution of innovation concepts into five phases.

The first phase was during 1950s to mid-1960s. At this time, the capitalism experienced an intense advance in the industrial sector mainly with expansion of new businesses based on new technological opportunities. This expansion was primarily supported by government's policies which stimulated investments in Research \& Development (R\&D) by the supply side of the economy. According to him, more investment in R\&D might result in successful innovative products. After the II World War, as a result of expansion of industrial businesses and growth of technological innovations, intensified the increase of competition and fight for market share

The second phase (mid-1960s to early 1970s) was marked by new organizational and marketing strategies. Organizational (internal) and market (external) factors had extraordinary impact on the innovation process. This phase was characterised by "market-pull innovation" and new investments in R\&D were driven by market elements and needs. Thus, market, not other area, occupied the central role of the process of innovation.

Even though, investments in R\&D and new technologies were still crucial and necessary, they were no longer sufficient enough to the development of new services and product (European Commission, 2004).

In late 1970 s to mid 1980s, innovation processes were characterised by the need to rationalize resources, cost control and reduction mainly due to the oil crises which had affected many countries and organizations. During those years, the innovation process was characterised by severe resource rationalization and limitation and reducing the incidence of wasteful failures. The new innovation concept was in essence a balance between technological-push and marketpull theories (coupling model). This model, according to Rothwell and Zegveld (1985), linked organizational functions to market and technological agents.

In the next phase (in mid-1980s to early 1990s), Rothwell called attention to what he named "the parallel and integrated model". This phase was characterised by the strengthening of new links between organizations and other market agents and the recovery of the global economy. Also, it was characterised by the notion of global strategies, new information and communication technologies and technology-based firms, quality-oriented production processes, the increasing of strategic partnerships between organizations, in particular, the engagement of micro, small and medium firms and the gradual increasing of networking activities. 
In this phase emerged the concept of innovation system. Firms were linked to a set of actors through interactive and collaborative networks. At this time, external sources (universities, suppliers and others) of knowledge and information generation were linked to the increasing of firm's innovativeness ((European Commission, 2004).

In the last phase (late 1990s), innovation is the technology itself. In areas such those linked to information and communication technology (ICT), the innovation rate was extremely high and at the same time, the service and product life cycle became shorter. In this competitive environment, firms were forced to become "fast innovators" unless they could not survive.

The Rothwell's description of the historical view of innovation approaches suggests that the evolution from the closed model where innovation was developed internally to a more open model with strong presence of social ingredients, required organizations to acquire new capabilities such as to manage network of collaborative interactions and flexibility to get knowledge and information by a variety of different innovation agents (European Commission, 2004).

Nowadays, there seems to be a relative consensus that important innovation inputs such as knowledge and information became crucial to the development of innovation processes regardless these inputs are generated internally or outside by a wide range of different actors such as research centres and universities, leading to an open collaborative model of innovation.

\section{Knowledge-based economy and innovation}

All innovation theories since Schumpeter are somehow associated to generation and dissemination of knowledge and as consequence new technologies, which have accelerated new innovation initiatives, forcing organizations to adopt new practices rapidly. In the 21st century, these premises reinforce the crucial presence of knowledge (generation and diffusion) to innovation and therefore for the development of the firms and progress of nations.

The importance of knowledge to innovation is so important that authors, including Howells (2002) and Cooke (2002) proposed that the impact of generation, dissemination, use and transfer of knowledge on innovation in the present century may lead to transformations like those in the industrial revolution in the 19th century. According to Cooke (2002), the difference is that forces come from brains rather than machines. Also, Cooke (2002) called attention to another component: a systemic perspective based on dynamic communication networks with impact on local economic development which may lead to strategic alliances between firms, members of local systems of innovation.

Even though knowledge has presented itself as an important input of innovation, impacting the level of competitiveness at both: countries and firms, it was only by mid-1990s that studies on knowledge started to call attention to government and entrepreneurs. One of the reasons was the fact that knowledge and development of innovation was clearly associated to economic growth and development (Howells, 2002). To Howells (2002), generation, use and diffusion of knowledge to promote innovation which consequently stimulates economic progress, have impact on the capability and performance of firms; thus it is relevant to the economic and social development of countries.

Since then, other authors followed this idea. Some of these authors were Sbragia, Stal, Campanario and Andreassi (2006) and Abrunhosa (2003). To Abrunhosa 2003), knowledge is so relevant to the generation of innovation that it determines firms' and countries' success. To others 
like Sbragia, Stal, Campanario and Andreassi (2006), from the organizational level, knowledge is much more important than machines to generate sustained development and competitive advantage. Authors above agreed that the application of knowledge to various processes inside organizations lead to more competitive and innovative organizations.

In the 20th century, firm's competitive advantage had been generated from the control and accesses to sources of raw materials, cheap labour and financial resources; in the 21st century, competitive advantage is a result of knowledge generation and the speed of learning processes of organizations. Nowadays, authors are paying attention to how knowledge impacts innovation, productivity and economic development. There is no doubt that the success of firms in this century is intrinsically linked to the quality of knowledge applied in corporate processes. Finally, they also agreed that as knowledge resides in people's mind mainly, it can be easily used to generate more knowledge.

The main challenge in this new economic perspective based on knowledge is not only how to generate and acquire new knowledge and information but also how to apply them. According to authors such as Madhok and Tallman (1998), knowledge may come from internal or external sources and implementation may require some kind of partnerships, networking or support. These sources are: (i) firms develop and create new resources internally, (ii) firms buy them from the market, (iii) it involves the acquisition of the firm itself which possesses the resources or new technologies or finally, (iv) firms acquire the resources through cooperative partnerships.

Differently from the past, in recent years, there was a substantial growth of new innovative initiatives as a result of search of new knowledge from external sources more than organizational one, mainly through cooperation of organizations and partnerships. The developments of new uses of technologies have accelerated the formation of partnerships which resulted in exchange of new knowledge from external sources even if partners are not geographically close. Successful innovative firms are those which not only manage internal knowledge flows, but also build cooperative partnerships and networks of relationships beyond firm 's boundaries, transforming those inputs into innovative products and services. New organizational strategies are driven by interactions, cooperation and networks of relationships, consisting of knowledge producers and users throughout different spatial systems of innovation.

Crescenzi and Rodriguez (2006) presented empirical evidences of how spatial systems of innovation at different levels (e.g. local, regional and national) impact the diffusion of knowledge spillovers and how they improve innovation capacity through stimulating interactions between different sources of innovation. One of these examples is the case of Europe where geographic proximity was relevant to the facilitation of the diffusion of knowledge. Even though, geographic proximity is relevant to innovation, organizations try to reach knowledge and other sources of innovation regardless of whether they are spatially close or not, as in large scale, innovation depends on the generation of new knowledge and firms must search for new knowledge and information sources to systematically sustain their competitive advantage (Melo, 2011).

Recent literatures on the influence of knowledge on innovation suggest that this is an interactive process and may take place within or/and across firms and other innovation agents; thus, from the external perspective, the process of innovation is based on an interactive model between organizations and the environment in the wide sense (Svetina and Prodan, 2008; Santos, 2000) 
According to the Oslo Manual (OECD/Eurostat, 2005), external sources of innovation may be classified into two main groups: Market/commercial and educational/institutional. Market sources of innovation are as follows: suppliers, clients, competitors and consultants. Universities, private research centres and government agencies are the main educational/institutional sources. Also, the same manual suggests that there are three different origins of new knowledge from external sources: i) open sources of knowledge and information; ii) acquisition of innovation inputs, especially knowledge or new technologies through purchases of capital goods or services and finally iii) acquisition of innovation inputs through co-operation arrangements with other enterprises or institutions (Melo, 2011)

From the organizational perspective, firms must invest in training and education programs to improve the internal capacity of generation of knowledge and creativity inside organization. Thus, innovation outcome depends on how organizations improve their capabilities and conditions able to stimulate the continuous learning process among employees (Melo, 2011).

In the context of global competitiveness, both external and internal knowledge sources are important references to new solutions for operational and organizational problems and may happen differently according to the size of organizations. Regarding to size of firms, in micro and small sized organizations knowledge transfer strongly relies on external knowledge sources; on the other hand, in the large organizations, this process happens through interactions among firm's internal departments (Svetina and Prodan, 2008).

Finally, the analysis of the selected literature suggests that innovation is a result of knowledge, experiences and abilities to create new products, processes and services (Tidd, Bessant and Pavitt, 2001); thus, innovation is also a result of the practical use and application of knowledge generating new knowledge and technologies. New knowledge generates more new knowledge, stimulating a virtuous innovation circle. In the 21st century economy, innovation plays a central role at the heart of economic development and is seen as vital to keep economies moving forward. The challenge now seems to be not the generation of new knowledge by itself but to improve the firm's ability to use it (Melo, 2011).

\section{Innovation from the Sociological perspective: networking}

Innovation is a phenomenon that has been explored by a variety of perspectives: geographic, economics, business management and sociological dimensions most of the time trying to explore this phenomenon from their own point of view. Some academics consider innovation as an economic phenomenon only; however, it involves other aspects such as sociology, as social structures can influence innovation processes and outcomes. It is interesting to notice that even though each dimension has their own perspective, they are related somehow; however, rarely, authors try to combine different perspectives in an interdisciplinary kind of way to explain innovation. Considering the economics and sociological perspectives only, Gordon and McCann (2000) argued that all economic phenomenons are socially embedded in the sense that they depend upon norms, institutions and sets of assumptions shared among a group of actors and are not simply the outcome of economic decisions.

This social perspective of innovation has been studied by authors such as Bessant and Tidd (2007) who related innovation to the changes in the society due to the development of new technologies. In this sense, the examination of the social perspective is important to the complete 
understanding of the innovation phenomenon. Rothwell (1994) explained that innovation may be associated to the result of the expansion of the networked model and the increase of technological changes. He recognizes the importance of the social interaction of different actors in the innovation process. It seems to be that successful innovation is a result of a combination of social elements and ideas which must be based on a landscape of abundant cooperation and networking (Chesbrough, 2003).

In fact, Chesbrough's proposition is a social interpretation of Schumpeterian vision of the process of innovation which stresses innovation as a result or combination of internal and external factors able to generate wealth.

The ideas discussed above suggest that successful innovation has strong connections to sociological aspects which depends on how firms interact and cooperate with other social actors and not only on the firms themselves (Smith, 1995). As an example, in particular cases such as those related to eco-innovation strategies, they have demanded firms to search for external skills and competences, therefore have required open innovation strategies (Laperch and Picard, 2013).

As consequence, this social perspective suggests that firms which do not interact and cooperate may reduce and limit their ability to enter into exchange relationships leading to failure in the process of development of innovations (Pittaway, Robertson, Munir and Neely, 2004)

In the 21st century economy, which is characterized by three features: it is global, informational and networked (Castell, 1999), innovation seems to be a result of the increase of social aspects such as

It is a consensus among many actors such as entrepreneurs themselves, scholars and policy-makers that in the 21st century economy, the innovativeness of firms is a result the increase of networks of innovation agents interacting collaboratively in an extensive process of exchanging information, knowledge and competencies. So, networks which facilitate access to knowledge and new technologies may serve as a new locus of innovation (Nelson, 1990); therefore, that the main locus of innovation has changed from the firm itself to the network it is embedded (Powell, Kenneth and Laurel, 1996).

So, a new approach linked to innovation came up: Networking. Networking is a complex idea and may assume a variety of forms in order to attend specific objectives. In terms of business, it is created with the objective to face pressures and challenges of the external environment reducing or diminishing pressures, facilitating access to innovation inputs such as knowledge leading to competitive gains (Oliver, 1990). From the innovation perspective, for instance, it may reflect the search of competitive gains which could not be obtained by individual efforts (Balestrin and Verschoore, 2008).

Networks, is the locus of networking and in general, they foster cooperation, allow organizations to enhance the learning process, open new channels for information exchange, facilitate the transfer of knowledge and lower risks and cost among their members (Hunt, Doyle, McDermott and McCormack, 2005). Being more specific, organizational networks may be seen as a group of firms in cooperation to each other to develop projects with the goal to achieve collective efficiency, to overcome common problems and to penetrate markets beyond individual reach (Unido, 2001). To Tidd (et al. 2001), they seem to be consisted of a number of 
positions or nodes, occupied by economic agents (i.e. firms, universities, government etc.) linked by interactions between nodes.

To Granovetter (1973), the network structure is formed by ties, which can be strong or weak. His argument has strong influence of sociological aspects and seems to be consistent as organizations with weak ties are more likely to turn diverse and non-redundant information to their own benefits. The presence of weak ties may create bridges to access new information from outside; therefore, increasing the chances of network members to become more innovative. Strong ties, on the other hand, seem to stimulate trustful interactions; however, are more likely to create redundant information flows, which it is not useful to increase firm's innovativeness (Melo, 2011).

From the organizational point of view, there are two network structures: transactional and informational. Some authors such as Contractor and Lorange (2002) gave more attention to the informational flow much more than transactional one. This is justified due to the increase of the flows of knowledge and information inside the networks and between network members resulting in substantial gains of innovativeness for the firms.

There is no doubt among academics that networking is of immensurable importance for firms in the search of new sources of knowledge and competences focusing on gains in innovativeness and competitiveness; however, it is not reasonable to believe that it happens by itself. Collaboration is an important pre-requisite for networking and come from the changing of the external environment, particularly in the business field (Child and Faulkner, 1998). Even though collaboration seems to be relatively easy, most of the time it is not so easy to practice it, unless network members see any benefits.

This theme (collaboration) is at the centre of discussion about networking, whether at personal, social or organizational levels. According to Gray (1996) collaboration, in the organizational context, is an antidote to problems by building collective capacities to face turbulent conditions.

Collaboration may be defined as "(...) a process whereby two or more parties work with each other to achieve mutually beneficial outcomes" (Miles, and Snow, 2005, p. 40). In the business context, collaboration may be said to be organizations working together for a common purpose and it is manifested through collaborative arrangements. These arrangements may be structured from a wide range of typologies such as alliances, joint-ventures, sub-contracting, cross-licensing, coalitions, consortia and business networks (Tidd, Bessant and Pavitt, 2001).

It seems that there is no doubt that collaborative arrangement through networks has many benefits. Specifically in the organizational context, they encourages firms to learn from each other, exchange experience and ideas and help firms to individually and collectively achieve economies of scale improving their competitive position (Unido, 2001). These benefits help firms to improve their capacity to become more innovative; therefore, it brings immense benefits to all members involved; however, it does not seem to be a natural-born strategy and firms to be engaged in any collaboration arrangement demands some kind of stimulus (Melo, 2011).

To authors such as Child and Faulkner (1998), these stimuli may come from the changing and dynamic external environment. Porter and Fuller (1996), suggested that other stimuli may come from the need to reduce risk, the search of economy of scale, response to government or market pressure or the need for new technology or market access. To Contractor and Lorange 
(2002), firms may be engaged in collaborative arrangements, also, because they want to block competition, to facilitate initial international expansion and to get vertical quasi-integration advantages of linking complementary contributions of the partners in the "value chain" and technology exchanges (Melo, 2011).

From the sociological perspective, firms engaged in collaborative activities seem to improve their level of competitiveness and innovativeness due to the fact that belonging to networked arrangements; they are stimulated to interact with each other with immense gains in the exchange of knowledge, information and competences.

Overall, according to Huxham (1996), the key motive in any firm to be engaged in collaborative arrangements is the focus on outputs of collaboration that could not have been achieved individually. These motives reflects the synergy between partners and are translated into the achievement of competitive advantages faster, cheaper and with less risk and disruption to operation (Hunt, et al., 2005). To Huxman (1996), even though there are many changes in aspects such as aims, language and perceived power, collaboration between organizations seems to happen due to the perception of mutual gains; however, it does not mean that this perception of mutual gain implies that self-interest is at the expense of others.

In this sense, from the organizational point of view, collaborative arrangements such as business networks are emerging as a powerful tool to promote the generation and diffusion of new knowledge and technologies leading to the overall improvement of firm's performance, impacting their competitiveness and innovativeness. Authors such as Cortrights (2006) and Ahuja (2000) have argued that to succeed, organizations have to network and collaborate to each other and firm's innovation activities are directly linked to the number of interaction linkages that they maintain.

Thus, business networks are network structures in which firms make relational contracts (formal or informal) with each other through a set of linkages to facilitate the exchange of information and technologies (Cooke, 1996). The difference between them relies on the structure of interactions. If from one side, formal business networks lead to a contractual dimension of relationship, informal one seems to demand no formality, but also with the same objective and based on trust. Informal networks are based structured on mutual trust and perceptions of benefits (Balestrin and Verschoore, 2008) and seem to allow transfer of tacit knowledge more easily than the formal networks (Unido, 2001).

Another author, Mohannak (2007) emphasizes the idea that business networks also improve the efficiency of the firm's innovative capability. Thus, the network environment creates a perception of collaboration and mutual benefits to all network members, which is important for the increasing and improvement of firm's innovation capability.

In general, the selected authors seemed to suggest that business networks, in essence is a collaborative arrangements, much more than a simple case of association or agglomeration of businesses and other economic agents in which interacting with each other and having common objectives, are able to facilitate flows of knowledge and competencies, improving innovativeness collectively. This scenario reinforces and amplifies the understanding of the OECD (2007) that in the contemporary economies, innovation is not seen as a solitaire phenomenon, results of the evolution of scientific and technological changes, but also a social phenomenon in which 
different actors must interact with each other in a constant flows of exchanging information and knowledge.

Hence innovation seems to be related to internal and external factors and even though firms seem to be the cradle of innovation, they are strongly influenced by external factors such as access to innovation sources, infrastructure, government policies and networks they are embedded (Melo, 2011). The synergy between these factors seems to create an appropriate environment able to promote conditions to increase firms' innovativeness. Setting this scene, to these authors innovation seems to be a result of three basic elements and can be written as a formula: Innovation = KFC: K = Knowledge (generation and diffusion), F = Faith (in the internal and external factors) and $C=$ Creativity (the practical use of knowledge) (Melo, 2011).

So, the conceptual frame of reference from which this paper was founded and the selection of authors for the development of this paper reflects predominantly the logic that suggests that as innovation seems to be a complex and multi and interdisciplinary phenomenon that cannot be explained by a single theory or dimension; thus, the more likely concept of innovation seems to be the one which takes into consideration elements of interaction in a constant flow of exchanging competencies, knowledge and information.

Finally, these authors may conclude that innovation seems to be a result of the freemarket system, interactions between various innovation agents as well as the intervention of government in the sense of fostering prosperity through policies that stimulate and support companies to compete efficiently. Therefore, firms tend to respond to those stimuli through innovative projects which enable them to compete in such a dynamic and globalized world. The outcome is that firms do not seem to be the locus of innovation itself, but the environment and network in which they are embedded (Powell, Kenneth and Laurel, 1996).

\section{THE CHANGES IN THE ECONOMIC SCENARIO IN BRAZIL SINCE THE EARLY 1990s}

Giving that the development of innovation initiatives is strongly influenced by global and country's economic contexts, examining economic transformations during the past twenty years in Brazil is very relevant for the understanding of the innovation performance of Brazilian firms.

Even though some important measures were taken, most of them were relatively modest; so, the impact on the level of innovativeness of firms was considered insignificant. Before 1990, past governments insisted firmly to prioritize the domestic market as opposed to an export oriented strategy (closed economy). For over fifty years, Brazilian governments decided to create a strong and self-sustained domestic market through the implementation of strategies which prioritized investments in the development of national industries with national technology as opposed to what other countries were doing (i.e. Chile and Korea). This strategy was implemented with strong import controls, including not only foreign product/service but new knowledge and technologies. This lead to an environment relatively averse to new technologies and the country's industries became obsolete which reflected directly in the low level of innovativeness of Brazilian firms.

Since the early 1990s, however, Brazil has faced many challenges in the political, social and economic fields. In the past twenty years, the Brazilian democratic regime was re-established, the country's presence in world markets was expanded with a relative 
liberalization of the economy, inflation was under control and poverty reduction policies were seriously implemented. However, such political, social and economic measures were not enough to place the country comfortably in the world scenario. The acceleration of the process of globalization during those years has demanded from countries faster and more efficient decisions. Much more has to be done in order to guarantee a sustainable integration of the national economy into the international scenario, particularly in today's serious crisis due to lack of governance and high level of Corruption (Melo, 2011).

Other efforts such as the legal environment were also implemented to provide conditions to the improvement of a country's innovation performance. In Brazil, as far as legislation is concerned, was established a group of laws to foster firms to innovate. These laws were specially focused on two pillars: i) Lei da Inovação, 2004 (Law of Innovation); ii) Lei do Bem, 2005 (Law of good), iii) Lei geral da micro e pequena empresa, 2006 (General Law for micro and small enterprises).

However, in a long term, this technological and trade isolation reflected in the loss of competitiveness in the international scenario. Thus, the combination of legal, economic and political measures was not able, by themselves, to stimulate entrepreneurs to invest in innovation projects. This scenario has affected seriously country's innovation performance.

\section{METHODOLOGY}

To writers such as Curran and Blackburn (2001), the design of a conceptual framework is the first step in carrying out any research. Overall, the conceptual framework is the basis of thinking about why and how the researcher undertakes a research. It describes the choice of the researcher which in essence is based on his/her understanding and perception of the problem. There are many paths to investigate a certain phenomenon and to determine the most suitable methodology. Then, researcher should base decisions predominantly on the understanding and perceptions of the problem as the choice of the research's stances leads to practical implications for conducting and designing the research (Creswell, 2007).

In this paper a survey strategy was developed. As a data collection method, the researchers adopted the interviewing strategy as the primary source of data collecting through a structured questionnaire. The questionnaire used was based on the recommendations of the Oslo Manual methodology (OECD/Eurostat, 2005) for innovation surveys; so that may be more consistent and reliable.

To approach the research problem it was decided to focus on technology-based micro and small firms in Campinas and Recife (Porto Digital Cluster) in Brazil. The reason for these choices was the fact that two of the most advanced technology-based business arrangements in Brazil are based in these two cities: Porto Digital in Recife, State of Pernambuco and the Technology Pole in Campinas, State of São Paulo. Both cities are internationally recognized as centers of excellence in technology-based firms supposedly highly innovative.

The Porto Digital Cluster in Recife, it's located approximately 100 hectares-island in the old part of Recife downtown in the Northeast region of the country. It is an advanced pole of software development and characterized by the presence of high tech and digital enterprises. On the other hand, the Technology Pole in Campinas, it is located in the Southeast region, and it is considered the richest and most industrialized region in Brazil. Also, due to the presence of 
one of the top five universities in Brazil, University of Campinas (Unicamp), good infrastructure, availability of skilled and talented labor force and high number of technology-based industries, the region is considered the Brazilian "Silicon Valley".

Classification of firms by size is an important element when dealing with innovation activities, since firms react differently to economic stimuli and have different needs, when they are in different size classes. Actually the Oslo Manual (Oecd/Eurostat 2005) methodology suggests that size of firms in any economic segment should be measured on the basis of number of employees as follows: Micro firms: 10 or less employees e Small firms: 11 to 50 employees.

As far as micro and small sized firms are concerned, they became very important players as almost half of innovations introduced into the market after World War II was generated by small firms (Timmons, 1990). Even though micro and small sized firms seem to be as innovative as large organizations, they use to face many problems. These problems may range from low level of their labor force, difficult to access new knowledge, technologies and credit to economy of scale (Sachs, 2002).

To gather the data, people in firms were asked to evaluate a pre-defined list of problems hampering innovation activities. These problems (It involves economic: high costs, lack of funds and lack of finance), knowledge (lack of skilled personnel and lack on information on technology), organizational (organizational rigidity) or market (lack of demand or need to meet norms and regulations) factors) are according to the methodology suggested by the Oslo Manual (OECD/Eurostat 2005); and each one was asked to determine degree of importance: i) major problem, ii) a bit of a problem or iii) not a problem.

Furthermore, other factors that may hamper innovation were considered related to the level of interactivity of firms' surveyed following the ideas of Chesbrough (2003) who considers that innovation processes combines both internal and external ideas and should be based on a landscape of abundant knowledge and cooperation; therefore, the level of interactivity is highly relevant to the development of innovation activities. So, in order to investigate problems and difficulties to the development of innovation initiatives, it is important to understand what factors may block or inhibit interactions between innovation agents.

A list of eight problems based on the Oslo Manual (OECD/Eurostat 2005) methodology was presented to each respondent to find out the problems hampering interactions: lack of trust, personal resistance to network, organizational culture, competitive sector, lack of network facilitator, lack of face-to-face interactions, lack of personal relationship and lack of channels of communications.

Overall, the relevance of these issues are directly related to the understanding of whether these factors really represent a problem to innovation, and to help firms to overcome these barriers, allowing them to be as innovative as they can.

\section{RESULTS}

Innovation is one of the most important themes in the business literature in the last fifty to sixty years and as a multifaceted phenomenon demands a more complex series of studies to explain in what conditions innovation is allowed to happen. Despite there are many aspects involved in the study of innovation, it is known that with the advance of new technologies, in 
particularly, communication technologies, organizations have changed their behaviours and are interacting more easily with an infinite number of partners whether they are physically close or not. As innovation is not free of problems, another relevant aspect is the understanding of what kind of problems are hampering, blocking or inhibiting innovation.

So, this paper focused on this aspect: the examination of problems which are hampering the increasing of the level of innovativeness in the micro and small technology-based firms in Brazil. Problems or obstacles are always a major concern for entrepreneurs and policy makers and need to be properly examined. Therefore, this study investigated the main problems which may hamper or block innovation activities in Brazil, from the perspective of micro and small technology-based enterprises. So, based on data gathered, this section describes some empirical findings which may allow clarifying the understanding of what factors are hampering or blocking a satisfactory improvement of Brazil's innovation performance.

Firs the study showed that Recife and Campinas were characterized by a specific size of firms: in Campinas, the majority of firms (74\%) were micro firms, and in Recife, $69 \%$ were small firms. As far as innovation rate is concerned, both locations were really innovative. In Campinas, for instance, $95 \%$ of the firms surveyed were engaged in innovation activities. In Recife, the study showed that $100 \%$ of firms surveyed were engaged in the development of innovation projects.

Another relevant finding from this study was that innovation may be influenced and related very closely to factors such: economic, knowledge, market and organizational as well as firms' interactions with external agents of innovation such as: universities, government agents, private and public research institutes, financial agents, customers, suppliers, competitors etc. All firms surveyed, both in Campinas and Recife, had interaction experiences to develop their innovation initiatives, and hence innovation seems to be actually an interactive phenomenon. These interactions happened as a combination of both: internal (organizational) as well as external sources of innovation. The findings showed that as considering external sources, firms surveyed used to interact with partners regardless of geographic distance.

Regarding interactions, the findings show that in Campinas, "lack of trust", "organizational culture" and "lack of networking facilitator" are the most significant problems hampering interactions. In Recife, the most significant problems hampering interactions are as follows: "lack of trust", "organizational culture" and "lack of face-to-face interactions". Overall, from the organizational point of view, lack of trust and organizational culture seem to be the major problems hampering innovation activities in Brazil.

Despite problems hampering interactions, results also showed that other problems contribute to inhibit the development of innovation initiatives. Almost $70 \%$ of problems cited by the firms surveyed in Campinas reported that economic problems (lack of funds, finance and high costs of innovation) are the most relevant, followed by knowledge (20\%) and Market problems (11\%). In Recife, it is not different from Campinas. The findings present that "lack of finance", "lack of funds" and "high costs of innovation" are the major problems blocking or hampering innovation activities also representing $70 \%$ of the problems.

Overall, considering the categories of factors hampering innovation activities (economic, knowledge, market and organizational), problems classified in the economic category (70\%) were the major problems, followed by market (14\%), knowledge (11\%) and organizational (4\%). As 
far as interactions are concerned, lack of trust and organizational culture are the most relevant factors.

\section{CONCLUSIONS}

The results of this study indicate that whereas problems exist, firms tend to overcome these problems to innovate and gain competitive advantages; however, apparently, the speed of changes and innovation initiatives are somehow affected or inhibited by these problems. Overall, the empirical evidences seem to show showed that:

i) Firms surveyed are highly interactive and these interactions have direct impact on their innovation performance;

ii) External factors such as the economic ones are the most relevant problems hampering innovation initiatives in Brazil. These are related to: lack of finance of existing projects, high costs of innovation and lack of funds to finance new innovation project;

iii) As far as interactions are concerned, factors such as lack of trust and organizational culture are the main limitations to the increase and improvement of quality of interactions.

iv) As a whole Brazil, does not seem to have yet an "innovation friendly environment", that is to say places where business arrangements, regions with the appropriate set of conditions that may promote and facilitate sustainable innovative initiatives.

These findings are in agreement with the model described by Rothwell (1994) in his fourth stage of innovation theories in which innovation is a result of a strategic networking approach rather than a result of the technology-push and market-pull approaches. Therefore, the external environment has significant influence on the development of innovation initiatives.

Whereas in the past, models of innovation such as the "triple helix", proposed by Etzkowitz and Leydesdorff (2000), appeared to be a consensus among entrepreneurs, scholar and policy-makers to explain the innovation phenomenon; in the 21st first century, these models are much more complex and involve a network of multi-variety types of innovation partners (i.e. universities, government agents, private and public research institutes, financial agents, customers, suppliers, competitors etc.)

In fact, empirical evidences suggested that innovation arises in many contexts involving, for example, the way how local conditions and relationships between the various innovation agents facilitate and impact the development of innovative initiatives. These create a feeling of gains and benefits generating the development of innovation activities with significant impact on the economic development of the city, region and country.

Overall, this study suggests that despite Brazil has being improving general conditions to do business in the country, as far as Brazil's innovativeness conditions is concerned, the country is still far from ideal fostering innovation conditions. Problems such as lack of fund and financing mechanisms, an appropriate infra-structure of access to knowledge sources, legal maturity, macroeconomic stability, government support, availability of educated and skilled labour, as well as organizational resistances to innovate play an important role that hampers innovation initiatives.

Finally, this paper provide some insights that may stimulate more research to identify problems hampering innovation in Brazil and other Latin American countries, since as mentioned before, based on the latest GII report, the region as a whole, regarding innovation, is still far behind 
compared with developed countries. Moreover the study suggest that some conditions such as improvement of education, research \& development, new fund and financing mechanisms and regional strategic alliance, sustainable economic conditions and others, may help to promote conditions to attract, develop and maintain innovative businesses; and initiatives like the GRI's Sustainability Reporting Framework may help to foster this process.

The company does not expose and therefore does not share in a visible manner their mission, vision and values. This is necessary for the process of the company's transparency before their target public. According to the authors mentioned in this study, this sharing is reflected in the strong organizational identity allowing the employees to have access over the positioning and future of the company they are part of. The management seems to us a little centralized on the leader what makes difficult the decision making and succession plan in the company. We also had the impression that by 2015 vehicle $\mathrm{J} 5$ will be launched in the world market as a hybrid, that is, a car that can be either electric or fuel driven.

Therefore we recommend the company to act strongly on sustainable processes for the manufacturing of automobiles as demonstrated in this article by GM do Brasil that has a technological center built in accordance with the concept of "Green Building", that focus to reduce the utilization of electric energy and natural resources in areas like stamping and painting. One of the main environmental principles adopted by GM is to reduce the generation of residues where all business units have composting practices, water recycling and reuse. Another initiative present in the painting of cars is the utilization of paints with higher solid content in order to increase yield and less solvent which results into less emission of organic compounds. GM also values the suppliers as business partners and hires them in accordance with their commitment with corporate responsibility. Upon these and other actions, the company diminished their costs resulting into more gains for the organization. However, one of the measures of sustainable management is the maintenance of jobs, and GM was called in by the Secretary of Treasury of the Ministry of Finance to provide explanations over their lay off plan at their plant in the city of São José dos Campos. The Brazilian federal government has a policy for tax reduction over industrialized products (called IPI in Brazil) for vehicles but on the other hand the government charges the companies the maintenance of jobs in the industry. "We give incentives both financial and taxes, and we want return on that" highlighted President of Brazil, Dilma Rousseff.

With these perceptions we can conclude that it is legitimate and significant for the country the entrance of foreign automakers, in the Brazilian territory, as for instance JAC Motors, main object of our study. Bringing to Brazil their projects for technological innovation focusing on the manufacturing of vehicles that are environmentally sustainable and at the same time on the integration of SHC group in the management of personnel that is compatible with the premises of sustainability, these are the major challenges to be faced and if addressed will be of higher significance for Brazil. 


\section{BIBLIOGRAPHIC REFERENCES}

Abrunhosa, A., 2003. The National Innovation Systems Approach and the Innovation Matrix. DRUID Summer Conference 2003 on Creating, Sharing and Transferring Knowledge.

Ahuja, G., 2000. Collaboration networks, structural holes and innovation: a longitudinal study, Administrative Science Quarterly, Vol. 45, pp. 425-455, USA.

Balestrin, A., Verschoore, J., 2008. Business Cooperation Networks, Bookman, Porto Alegre.

Bessant, J., Tidd, J., 2007. Innovation and entrepreneurship, John Wiley, Chichester.

Best, M., H., 1990. The new competition: institutions of industrial restructuring. Cambridge: Harvard University Press.

Castell, M., 1999. Materials for an exploratory theory of the network society Available at: < http://www.scribd.com/doc/7321227/Castells-Manuel-Exploratory-Theory-NetworkSociety >. Accessed on 4th June 2014.

Chesbrough, H., 2003. Open Innovation: The new imperative for creating and profiting from technology. USA: Harvard Business Press.

Child, J., Faulkner, D., 1998. Strategies of Cooperation: Managing alliances, networks and joint ventures, Oxford University Press, Oxford.

Contractor, F., J., Lorange, P., N., 2002. Cooperative Strategies and Alliances, Elsevier, UK.

Cooke, P., 1996. Networking for competitive advantage: Including enterprise support policies in European region, report prepared for National Economic and Social Council, Dublin.

Cooke, P., 2002. Knowledge Economies: Clusters, learning and cooperative advantage, Routledge, London.

Cortrights, J., 2006. Making Sense of clusters: Regional competitiveness and economic development, discussion paper prepared for the Brookings Institution Metropolitan Policy Program, USA.

Crescenzi, R. and Rodriguez, A., 2006, R\&D, Spillovers, Innovation Systems and the Genesis of Regional Growth in Europe, BEER Paper no. 5.

Creswell, J., W., 2007. 2nd Edition, Qualitative inquiry \& research design. USA: Sage Publications. 
Curran, J., Blackburn, R., A., 2001. Researching the small enterprise London: Sage publications.

Drucker, P., F., 1986. Innovation and Entrepreneurship: practice and principles. London: Heinemann.

Etzkowitz, H., Leydesdorff, L., 2000. The dynamics of innovation: from national systems and 'Mode 2 ' to a Triple Helix of university-industry-government relations, Research Policy, Vol. 29, No 2, p. 109-123.

European Commission, 2004. Innovation Management and the Knowledge-Driven Economy, Brussels.

Global Innovation Index. The Global Innovation Index 2014. http://www.globalinnovationindex. org/userfiles/file/reportpdf/GII-2014-v5.pdf

Gordon, I., R., McCann P., 2000. Industrial Clusters: Complexes, Agglomeration and/or Social Networks? Urban Studies, vol. 37, no.3, p. 513-532.

Granovetter, M., 1973. The Strength of weak ties, The American Journal of Sociology, vol.78, no. 6, p.1360-1380.

Gray, 1996. Cross-Sectoral Partners: Collaborative Alliances among business, Government and Communities, In: Chris Huxham (Ed.) (1996), Creating Collaborative Advantage, p.19-43, Sage Publications, London.

GRI's Sustainability Reporting Framework. https://www.globalreporting.org/information /aboutgri/Pages/default.aspx.

Holmen, M., Magnusson, M., McCelvey, M., 2007. What are innovative opportunities? Industry and innovation, vol. 14, no.1, p.27-45.

Horbach, J., Rennings, K., 2013. Environmental innovation and employment dynamics in different technology fields - an analysis based on the German Community Innovation Survey 2009. Journal of Cleaner Production, vol. 57, 158-165.

Howells, J., Tacit, 2002. Knowledge, Innovation and Economic Geography, Urban Studies, vol 39, p. 871-874.

Hunt, M., Doyle, G., McDermott, D., McCormack, P., 2005. Business network on the island of Ireland, Report prepared for InterTradelreland, Ireland.

Huxman, C., 1996. (Ed), Creating Collaborative Advantage, Sage Publications, London. 
Brazilian Institute of Geography and Statistics - IBGE, 2002. Technological Innovation Survey, Rio de Janeiro.

Brazilian Institute of Geography and Statistics - IBGE, 2003. Technological Innovation Survey, Rio de Janeiro.

Brazilian Institute of Geography and Statistics - IBGE, 2005. Technological Innovation Survey, Rio de Janeiro.

Brazilian Institute of Geography and Statistics - IBGE, 2008. Technological Innovation Survey, Rio de Janeiro.

Brazilian Institute of Geography and Statistics - IBGE, 2011. Technological Innovation Survey, Rio de Janeiro.

Kiessling, T., S., Richey, R., G., 2004. Examining the theoretical inspirations of a management guru: Peter Drucker and the Austrian School of Economics. Management Decision, vol. 42, no. 10, p. 1269-1283.

Laperch, B., Picard, F., 2013. Environmental constraints, Product-Service Systems development and impacts on innovation management: learning from manufacturing firms in the French context. Journal of Cleaner Production, vol. 53, 118-128.

Madhok, A., Tallman, S., B., 1998. Resources, transactions and rents: managing value through interfirm collaborative relationships, Organization Science, vol.9, no.3, p. 326-339.

Melo, P., 2011. Innovation and firm's interaction behaviour: Is innovation associated with local or non-local interactions? An investigation of clustered micro and small technology-based firms in Brazil [PhD Thesis]. Ireland: School of Business of the Waterford Institute of Technology (WIT).

Miles, R., E., et al., 2005. Collaborative Entrepreneurship: How communities of networked firms use continuous innovation to create economic wealth, Stanford University Press, Stanford.

Mohannak, K., 2007. Innovation Networks and capability building in the Australian hightechnology SMEs, European Journal of Innovation Management, vol. 10 no. 2.

Motta, P., R., 1989. Management of new ideas: how to awaken creativity and overcome the impotence of inovacional desire? Rio de Janeiro: Magazine Public Administration, vol.23, no.4, p.71-86.

Nelson, R., R., 1990. Capitalism as an engine of progress, Research Policy, vol. 19, p. 119-132. 
Oliver, C., 1990. Determinants of inter-organizational relationships: integration and future directions. Academy of Management Review, vol.15, no.2, p.241-265.

Organization for economic co-operation and development (OECD) and statistical office of the European communities - Eurostat, 2005. Guidelines for collecting and interpreting innovation data, Oslo Manual, 3rd edition, Paris.

Organization for economic co-operation and development (OECD), 2007. National Innovation Systems, OECD, Paris.

Organization for economic co-operation and development (OECD), 1996. The Knowledge-Based Economy. Paris.

Organization for economic co-operation and development (OECD), 2000. Small and Medium Sized Enterprises: local strength, global reach. Paris.

Pittaway, L., Robertson, M., Munir, K., Neely, A., 2004. Networking and innovation: a systematic review of the evidence, International Journal of Management Reviews Vol. 5/6 Issue 3\&4 p. 137-168.

Porter, M., E., Fuller, M., B., 1996. Coalitions and Global Strategy, In.: Competition in Global Industries (p. 315-343), Michael Porter (Ed.), Harvard Business School Press, Boston.

Porter, M., E., 1998. The Competitive Advantage of Nations. London: Macmillan Press Ltd.

Powell, W., W., Kenneth, W., K., Laurel, S., 1996. Interorganizational Collaboration and the Locus of Innovation: Networks of Learning in Biotechnology, Administrative Science Quarterly, vol. 41, p.116-45.

Rothwell, R., 1994. Toward the fifth generation innovation process, International Marketing Review, vol.11, no. 1, p. 7-31, England: MCB University Press.

Rothwell, R., Zegveld, W., 1985. Reindustrialization and Technology, Longman, Harlow. Sachs, I., 2002. Human development and the future of small entrepreneurs in Brazil, SEBRAE, Brasília.

Santos, D., 2000. Innovation and territory: which strategies to promote regional innovation systems in Portugal? European Urban and Regional Studies, Vol. 7, no. 2,p. 147-157.

Sbragia, R., Stal, E., Campanario, M., Andreassl, T., 2006. Innovation: how to overcome this business challenge. Clio Editora, São Paulo.

Schumpeter, J., 1979. Capitalism, Socialism and Democracy. London: George Allen \& Unwin. 
Smith, K. (1995), Knowledge systems: Foundations, policy implications and emprirical methods, STI Review, Vol. 16.

Svetina, A., C., Prodan, I., 2008. How internal and external sources of knowledge contribute to firm's innovation performance, Managing Global Transitions, Vol. 6, no. 6, p. 277-299.

Tidd, J., Bessant, J., Pavitt, K., 2001. Managing Innovation - Integrating Technological, Market and Organizational Change, John Wiley \& Sons Ltd., England.

Timmons, J., A., 1990. New business opportunities: Getting to the right place at the right time, Brick House Publishing Co., MA.

Unido, 2001. Development of clusters and networks of SMEs, The United Nations Industrial Development Organization (UNIDO), The UNIDO Programme, Vienna. 